\title{
PREVENTIVE CONSERVATION OF VERNACULAR ADOBE HERITAGE LOCATED IN SEISMIC-PRONE REGIONS
}

\author{
N. Haji Sadeghi ${ }^{1, *}$, M. Correia ${ }^{2}$, D. V. Oliveira ${ }^{3}$, H. Azizi-Bondarabadi ${ }^{4}$ \\ ${ }^{1}$ Department of Architecture, Yazd University, Yazd, Iran - neda.hsadeghi@gmail.com \\ ${ }^{2}$ CI-ESG, Centro de Investigação, Escola Superior Gallaecia, Largo das Oliveiras 4920-251 Vila Nova de Cerveira, \\ Portugal - marianacorreia@esg.pt \\ ${ }^{3}$ ISISE, University of Minho, Guimarães, Portugal - danvco@ civil.uminho.pt \\ ${ }^{4}$ Department of Civil Engineering, Yazd University, Yazd, Iran - hamed.azizib@gmail.com
}

\author{
Commission II - WG II/8
}

KEY WORDS: Seismic retrofitting, Adobe vernacular heritage, Preventive conservation, Earthquake.

\begin{abstract}
:
In general, relevant actions to retrofit heritage should be considered before the occurrence of earthquakes. This proactive approach is preferred, rather than a reactive approach in an emergency situation, following the earthquake. These preventive actions are known as disaster mitigation, risk mitigation, disaster risk management, seismic upgrading and preventive conservation. In the case of vernacular heritage, poor workmanship, lack of financial support, vast number of buildings, and the use of weak material lead to the need to conduct efforts to develop preventive conservation methods with relevant criteria. All these actions were directed to protecting vernacular heritage from multiple potential damages that could threaten this architecture in the future. In recent years, records of casualty and losses due to earthquakes reveal that seismic events can be one of the most destructive potential damages for building, especially if constructed with a weak material, such as adobe. There is little literature concerning preventive conservation of vernacular adobe buildings, which are at risk from earthquakes. Vernacular architecture needs more consideration due to the high number of vernacular dwellings worldwide but especially due to the inhabitants' safety. Failure to recall the effects of destructive earthquakes with a large recurrent period of seismic actions, but also economic reasons lead to the neglect of these important preventive solutions. The main objective of this paper is to emphasize that a comprehensive conservation procedure related to prevention of casualties and damage of vernacular adobe heritage located in seismic-prone regions, should consider relevant principles and criteria for the conservation of cultural heritage. In the field of preventive conservation of adobe vernacular heritage located in seismic-prone regions, there is some confusion concerning the relation between the conservation process and the seismic protection process; the importance and need of conservation principles in seismic protection procedures; and also the role of the architect and of the engineer in these processes. These matters will be discussed in the current paper.
\end{abstract}

\section{INTRODUCTION}

Destruction of vulnerable construction such as adobe heritage in face of an earthquake causes real threats to the safety of inhabitants and also to the continued existence of vernacular adobe buildings. Due to this fact, there is a need for seismic upgrading of adobe heritage at risk of an earthquake. The majority of the research, regarding historical adobe buildings in seismic area, reflects on the structural and the technical aspects. Most of the research considers the terms seismic reinforcement, strengthening, retrofitting, stabilizing, protection and improvement of adobe buildings. In the engineering community, the expression conservation of adobe architecture in seismicprone regions is not of common use. There are only a few references regarding the historical earthen buildings in the seismic area with the title of "conservation of earthen architecture heritage" (Montes, Giesen, 2010; Vargas-Neumann, 2012).

Based on the body of literature, conservation is known as a process to prolong the life of heritage and preserve it for future generations with respect to their cultural and historical significance. Based on the Lima Declaration, the first priority of conservation of heritage in response to disasters, such as earthquake occurrence, is saving human lives. The preservation of historical features, the integrity, and the authenticity of the built heritage should be taken into consideration as the next goal in the conservation of heritage. However, it is important to balance between these two main objectives of the procedure: seismic retrofitting to provide safety, and preservation of historical and cultural values.

In a conservation process, conservation value and conservation principles are the two main issues contributing to the definition of conservation intervention criteria (Correia, Walliman, 2014). Conservation values have fundamental issues in a conservation process and help to systematically set overall priorities in choosing proposed interventions (Feilden, 2003). Conservation principles present the basic concepts of conservation.

In the case of heritage in seismic-prone regions, definition of seismic safety criteria instigates better decision-making for intervention strategy and techniques in the conservation process. Due to the diversity of seismicity in different regions, seismic safety criteria should be established for each region, based on their specific conditions related to the seismology and probable seismic events of each area. However, there are different intervention techniques and materials for adobe building stabilization.

\footnotetext{
* Corresponding author
} 
It is noteworthy to mention that methodology of conservation for heritage in seismic regions could be classified into two categories; conservation of heritage before a probable earthquake (pre-earthquake conservation) and conservation of heritage after an earthquake occurrence (post-earthquake conservation). The former has been considered in the current study. As stated in the goals of ICOMOS and ICCROM, creating a culture of prevention before the earthquake event is necessary and much more cost-effective, due to the fact that responding to emergencies following an earthquake cannot be efficient, especially when the damage is irreparable (UNESCO, 2010). Therefore, considering the vulnerability of the earthen architecture heritage in seismic-prone areas, conservation principles should focus on preventing the irreparable collapse of the structures during extreme earthquakes. Accordingly, it is important to evaluate the seismic safety before an earthquake occurs to be able to define an appropriate intervention strategy. This could result in seismic retrofitting and the saving of lives, while also preserving the cultural and historical value of the built heritage (Correia et al., 2014). Seismic retrofitting of the heritage before seismic events, which is a part of a comprehensive conservation procedure, could also be named as a preventive conservation of heritage.

The main objective of this paper is to emphasize the need for a comprehensive conservation procedure related to prevention of casualties and damage to vernacular adobe heritage located in seismic-prone regions, while considering the relevant principles and criteria for conservation of cultural heritage.

In the field of preventive conservation of adobe vernacular heritage located in seismic-prone regions, there is some confusion concerning the relation between the conservation process and the seismic protection process; the importance and need of conservation principles in seismic protection procedures; and also, the role of the architect and of the engineer in these processes. These matters will be deeply discussed in the current paper.

\section{FIRST QUESTION}

- Is the seismic retrofitting/strengthening process considered as a part of the conservation process or does it stand on its own?

In the field of cultural heritage protection in specific earthquake zones, between all the Charters and Declarations, reference can only be addressed to the Lima Declaration. Lima Declaration for Disaster Risk Management of Cultural Heritage (UNESCO, 2010) has been established by cultural heritage professionals, architects, archaeologists, structural engineers and other specialists in the "Symposium on Disaster Risk Management of Cultural Heritage, Sustainable Conservation of Urban Cultural Heritage in Seismic Zones". The Declaration emphasizes the need to establish comprehensive disaster mitigation for cultural heritage by expert committees and multidisciplinary specialists (ICOMOS, 2010, Art 6). Although, this declaration named the process of protection of cultural heritage in earthquake zones as disaster risk management, and not as a conservation procedure, it emphasizes that this procedure should be comprehensive and all encompassing.

The ICOMOS Charter of "Principles for the Analysis, Conservation and Structural Restoration of Architectural Heritage"(ICOMOS, 2003) and the ICOMOS/ISCARSAH "Recommendations for the Analysis, Conservation and
Structural Restoration of Architectural Heritage" (ICOMOSISCARSAH Recommendation, 2005) consider all the architectural heritage. It is noteworthy to mention that in their title, conservation and structural restoration (and seismic retrofitting could be a part of structural restoration) have been addressed individually. However, ICOMOS-ISCARSAH Recommendation (2005) recommends to provide decisions by the conservation team, as a whole and to take into account both the safety and the stability of the structure, as well as considerations of historical and cultural values of the fabric. D'Ayala (2014) also mentions the conservation team, and the seismic engineering community as two individual expert teams, although, the need for collaboration between these two teams has been emphasized more than once.

The majority of the research, regarding historical adobe buildings in seismic areas, considers the structural and the technical aspects. Most of the research considers the terms seismic reinforcement (Blondet et al., 2006; Vatandoust, Mokhtari, Nejati, 2008), strengthening (Sathiparan, Meguro, 2015; Sumanov, 1999), retrofitting (Michiels, 2015; Tolles, 2006; Tolles, Kimbro, Ginell, 2003; Varum et al., 2014), stabilizing (Barrow et al., 2006; Tolles et al., 2000), protection (Blondet, Aguilar, 2007) and improvement (Dowling, 2004) of adobe buildings. Usually in the engineering community, the expression conservation of adobe architecture in seismic-prone regions is not commonly used. There are a few references regarding historical earthen buildings in seismic areas with the title of "conservation of earthen architecture heritage" (Montes, Giesen, 2010; Vargas-Neumann, 2012). In Terra Literature Review, "Earthen Material Conservation" (Oliver, 2008) and "Seismic Damage of Earthen Structure" (Webster, 2008) have been embraced separately in different chapters.

The Getty institute named one of the research projects on historic adobe structure as "Seismic Stabilization of Historic Adobe Structures" which, provides information on how to plan for and access further information on the retrofitting of historical adobe buildings (Tolles et al., 2000). Another Getty project is, named "Planning and engineering guidelines for the seismic retrofitting of historic adobe structures", research and testing of adobe structures to evaluate retrofitting methodologies have been conducted to ensure safety standards while preserving the historic architectural fabric (Tolles et al., 2003). Although in a later project, the title of the project became Seismic Retrofitting, Tolles et al. (2003) claimed that seismic retrofitting was a specific type of structural stabilization or intervention, which was considered as part of the preservation treatment.

In the development of the conservation and seismic retrofitting projects performed in Peru by Cancino et al. (2016), the retrofitted projects followed a principles-based conservation approach, and two groups of engineering principles and conservation principles have been determined, in order to address decision-making. These retrofitting projects have comprised the recommended methodological component for a comprehensive conservation procedure and could be named as a conservation project.

It should be pointed out that seismic retrofitting actions were embraced as part of the broad-scope conservation programs or stand alone as an individual project. However, the latter entails providing a seismic retrofitting strategy consistent with conservation principles and coordinated by a multidisciplinary expert's group. 


\section{SECOND QUESTION}

\begin{abstract}
- In the seismic protection of adobe vernacular heritage, respecting the conservation principles is important and recommended, but how should this be evaluated? How can the conservation team distinguish that the proposed techniques are the most adequate?
\end{abstract}

All the preventive intervention and mitigation measures should have a minimum impact on the heritage values and on authenticity and integrity of a cultural property (UNESCO, 2010). Strengthening might be needed if the structure is vulnerable to hazards such as earthquakes. In the seismic protection of adobe heritage, respecting the conservation principles is important and recommended by all the Charters and Guidelines. The applicability and efficiency of intervention measures could be evaluated, but assessing their respect to the conservation principals, such as compatibility, reversibility, authenticity and integrity of the heritage, and applying a minimum level of intervention, is a complicated task.

The ISCARSAH principles, in addition to determine the more generic conservation principles, such as minimal intervention, compatibility, and reversibility of repair, introduce specified concepts for the structural and seismic behavior of heritage, which have direct consequences on their seismic retrofitting. The following concepts are presented:

- "Structural authenticity, which should be preserved as much as the architectural authenticity, ensuring that the original mechanical and resisting principles governing the structural response are not altered and original structural elements are not made redundant;

- Structural reliability relates to the necessity of striking the correct balance between the public safety requirements and the preservation requirements.

- Strengthening compatibility relates to the suitability of "new" materials and structural elements in terms of their physical and mechanical performance when compared with original materials and structural elements;

- Strengthening durability relates to the performance in time. The new elements should be durable as to extend the expected life of the original structures as intended;

- Strengthening reversibility relates to the possibility of removing partially or totally the intervention if monitoring proves that it is not suitable;

- Strengthening monitorability relates to the possibility of observing and recording the performance of the intervention solution, to determine its effectiveness." (D'Ayala, 2014, p.491)

In order to provide applicable and efficient conservation intervention techniques, it is fundamental to address architectural, historical and structural analyses of heritage. Hence, it can be stated that retrofitting strategies cannot be planned without identifying precisely specific information on the fabric. Tolles et al. (2003) state that in order to initiate consideration of retrofit designs for inhabited adobe buildings in seismic areas, information should be obtained on the probability of earthquake occurrence, the characteristics of the high- or low- magnitude of earthquakes that can be expected to occur, and also the types and location of historic fabric elements that require maximum protection.

For the upgrading of seismic resistance, there is a need to understand the nature of historical buildings, especially those that are built of weak materials such as adobe architecture (Feilden, 2003). However, Tolles et al. (2003) claim that structural stabilization and seismic retrofitting of historical adobe buildings typically have involved the sacrifice of traditional structural systems with the extensive use of structural materials that are mechanically incompatible with adobe. Indeed, such loss of traditional structural system leads to the destruction of the architectural and historical value at the cost of providing safety.

In the case of vernacular adobe heritage, lack of standardized experimental methods and assessment procedures for evaluating the performance of adobe structures cause problems during the safety evaluation and treatment measures (Illampas, Ioannou, Charmpis, 2011). The complexity of historical buildings; the uncertainty regarding material properties; the unknown influence of previous phenomena; the incomplete knowledge of previous alterations; and the repairs and the lack of information about the long-term impact of applied techniques are effective factors that makes it difficult to fully understand the historical architecture (ICOMOS-ISCARSAH Recommendation, 2005). Above the aforementioned reasons, lack of belief of some of the conservation experts regarding the importance of structural assessment and seismic safety evaluation of historical adobe buildings leads to incomprehensive conservation procedures.

For the seismic retrofitting of a vast number of vernacular adobe heritage which are in everyday use, besides performing a comprehensive understanding and safety evaluation of adobe construction, it is important to consider the availability and the cost of selected techniques and materials. Tolles et al. (2003) stated that funding problems are one of the greatest difficulties addressing seismic retrofitting projects. Heritage buildings with private ownership, such as the majority of adobe vernacular heritage, have encountered funding problems. In such buildings, the current use and future use of buildings and the number of permanent and temporary settlements are also effective parameters to establish intervention strategies. Sometimes, the effect of the aforementioned factors on defining the intervention techniques and materials exceeds the conservation principles effect.

One of the main problems of defining seismic retrofitting strategy for historical structures is to find the balance between structural interventions, and the preservation of historical and cultural values. Acceptance of the retrofit challenge will provide the longterm advantage of both historic fabric preservation and life-safety guarantee. There is no difference between loss of historic fabric following invasive retrofitting techniques and direct fabric destruction by an earthquake occurrence, as both are undesirable (Tolles et al., 2003). For this purpose, both the conservation principles and the heritage condition, architecturally, socially, historically and structurally should be considered. This makes it clear how the decision-maker should prioritize the public-safety concern and the preservation of the heritage value.

It is noteworthy that in the conservation process of a vast number of adobe vernacular buildings in seismic regions, it is impossible to provide a general technical guideline for all the buildings. In such procedures, each intervention method should be determined for groups of buildings, based on the studies of the building, its typology, building culture and context, the defined conservation criteria, and the proposed conservation methodology. In addition, the level of intervention of the conservation process should be identified considering the conservation objective and values, financial resources, building function, the life expectancy of the structure and the findings emerging from the building studies, addressing historical, architectural, structural and social terms. 
It should be pointed out that the best retrofitting solution for one building typology might not be an adequate solution for another one, in a different context or constructed with a distinct building culture. Besides, in order to specify the best solution, the responsible experts should suggest some practical alternatives for the conservation multidisciplinary team to consider. Furthermore, the compatibility of the proposals with the historic fabric together with an estimate for their influences must be taken into account by the team. In general, following the assessment on how the suggested solutions affect the values in the historical building and its significance, one of the best according to the Feilden (2003, p.130) is to choose the least bad' solution, considering the fact that every solution has pros and cons, in terms of cost, authenticity, durability, reversibility etc. The responsible team should generally answer the questions of whether the intervention is the minimum required, can it be replaced by future interventions, is the authenticity and integrity of the built heritage preserved, and many other questions regarding the respect of other conservation principles. However, the answers for these questions should never be "Yes" or "No" and should depend on many effective parameters. Ideally, the conservation team should endeavor to reach, an optimum solution for heritage in the seismic-prone region.

\section{THIRD QUESTION}

\begin{abstract}
- What is the role of structural engineers and conservation architects in the protection of cultural heritage located in seismic zones? Is seismic retrofitting of adobe heritage only an engineering problem?
\end{abstract}

Structural engineers have developed most of the works on heritage retrofitting located in seismic areas and have addressed a special focus on the technical aspects. Moreover, most of the research about earthen heritage, in particular adobe buildings, in seismic-prone regions have been developed by the engineering community. The research has been concentrated on physical and structural conditions, structural performance, material analyses and also special strengthening techniques. In the provided recommendations derived from such research, no difference between common buildings or valuable heritage is observed. Professionals often study just the physical aspect of earthen architecture (Blondet, Aguilar, 2007; Minke, 2001; Morris, Walker, Drupsteen, 2011; Tolles et al., 2000; Torrealva, Vargas-Neumann, Blondet, 2006; UNIPD, 2012; Webster, 2008). There is very little research that deals with principles addressing conservation of earthen architectural heritage in a seismic region (Correia, Walliman, 2014), and no relevant intervention techniques have been considered (VargasNeumann, 2012; Vargas-Neumann, Blondet, Iwaki, 2010). Through the revision of the literature, a few research projects have been identified with a focus on the specified adobe monument or archaeological site in the seismic-prone regions (EERI, 2004; Maïni, 2004; Manafpour, 2003; VargasNeumann et al., 2011; Webster, Tolles, 2000). It should be stated that the Getty Conservation Institute has conducted one of the projects that has tried to identify and evaluate seismic retrofitting methodologies, in order to create a balance between providing safety and the conservation of cultural heritage. The title is Planning and Engineering Guidelines for the Seismic Retrofitting of Historic Adobe Structures (Tolles et al., 2003).

Feilden (2003, p.125) states that the greatest danger to historic buildings comes from engineers that are not concerned about heritage values and just apply the codes or the engineers who are unwilling to take the responsibility of making judgments. It is observed that some historic buildings have been severely damaged by the incorrect use of codes and standards before the earthquake occurrence. This could be due to the absence of awareness by non-qualified professionals, when addressing conservation of historical buildings. As a result of this gap, there is a tendency for some engineers to perceive conservation projects like new buildings and apply the same intervention techniques (Okten et al., 2016).

Regarding the fact that assessing seismic damage and providing recommendations for the strengthening techniques, are mostly conducted by seismic engineers, the following question arises: why is it necessary to engage an architect in the conservation process of heritage in seismic-prone regions?

Tolles et al. (2003) answered to this question properly:

The usual training received by engineers is focused on structural and life safety concerns, whereas the historical architect is trained to understand what needs to be done and by whom- to safeguard the historical, architectural, and archaeological features of the structure. This architect is also better able to deal with the important aesthetic and design issues... Architects are trained not only to oversee project planning but also to anticipate the possible consequences of altering existing buildings, especially with regard to the visual or aesthetic qualities. A preservation architect brings the additional qualifications of understanding the value of preserving historic fabric, knowing how to go about it, and being familiar with the appropriate specialists to entrust with various tasks. Also a preservation or historical architect, in consultation with the owner or site manager, can provide guidance in selecting the appropriate treatment. In contrast, engineers are adept at solving structural problems efficiently and cost effectively (Tolles et al., 2003, p. 28, 33).

Ochsendorf as a structural engineer specialized in the analysis and design of masonry structures and as a university professor, also addressed the same question:

The first responsibility of an engineer is to work closely with the other disciplines-historians to learn the history of a monument, architects to learn the design intent for future use, conservators to understand the challenges in terms of material conservation, and also the property owner to understand the owner's needs and challenges. Engineers must then offer a range of solutions that can be debated on their merits (GCI, 2015, p.19)

Based on the existing Charters and guidelines, planning for the seismic retrofitting of heritage requires the participation of multidisciplinary groups of specialists (ICOMOS, 2003, 2010; SESOC, 2013). The preservation architect and the engineer are the principal members of the design team and if necessary, a preservation professional or conservator, as a specialist in historical preservation of buildings may be added to the team. Moreover, according to the ICOMOS-ISCARSAH Recommendation (2005), engineers should provide the scientific support needed to obtain safeguard of the cultural and historical value of the building, as a whole. Therefore, it can be stated that decisions in conservation procedures should be the result of collaboration between all members of the conservation team. 


\section{CONCLUSION}

In general, conservation is known as a process to prolong the life of heritage and to preserve it for future generations respecting the cultural and historical significance. Therefore, as a preventive conservation procedure, there is a need to take an effective action to preserve adobe heritage located in high-risk regions, before disaster occurrence.

In seismic-prone regions, the engineering community usually performs the majority of upgrading actions of adobe buildings within retrofitting projects. However, in seismic upgrading of built heritage, the preservation of historical features, and their integrity and authenticity related to World Heritage Sites, represents key-roles. Hence, the retrofitting actions should be considered as part of a broad-scope conservation programs. Therefore, it is important to balance seismic retrofitting to provide safety and the preservation of historical and cultural value. It should be pointed out that seismic retrofitting actions sometimes stand alone as an individual project. However, it should entail a seismic retrofitting strategy consistent with conservation principles and coordinated by a multidisciplinary expert group. In the seismic protection of adobe heritage, it is important and recommended by all the Charters and Guidelines, to respect the conservation principles. Ideally, the conservation team should endeavor to reach an optimum solution for adobe heritage in a seismic-prone region, respecting the conservation principles as much as possible. For this purpose, both the conservation principles and the heritage condition, architecturally, socially, historically and structurally should be considered.

\section{REFERENCES}

Barrow, J. M., Porter, D., Farneth, S., Tolles, E. L., 2006: Evolving methodology in seismic retrofit: stabilizing the Las Flores Adobe. Paper presented at the Getty Seismic Adobe Project 2006 Colloquium, Los Angeles.

Blondet, M., Aguilar, R., 2007: Seismic protection of earthen buildings. Paper presented at the Conferencia Internacional En Ingeniería Sísmica, Lima, Peru.

Blondet, M., Vargas-Neumann, J., Velásquez, J., Tarque, N., 2006: Experimental study of synthetic mesh reinforcement of historical adobe buildings. In P. B. Lourenço, P. Roca, C. Modena, S. Agrawal (Eds.), Structural Analysis of Historical Constructions, New Delhi 2006. India: Macmillan.

Cancino, C., Torrealva, D., Vicente, E., Bryce, J. G., Soto, M., Cruz, E., Wong, K., 2016: The Cathedral of Ica and the Church of Kuño Tambo in Peru: Two retrofitting projects following a principles-based conservation approach. Paper presented at the Structural Analysis of Historical Constructions: Anamnesis, diagnosis, therapy, controls, Leuven, Belgium.

Correia, M., Carlos, G., Rocha, S., Lourenço, P., Vasconcelos, G., Varum, H., 2014: SEISMIC-V: Vernacular seismic culture in Portugal. Theme 5: Natural hazards and risk mitigation. In M. Correia, G. Carlos, S. Rocha (Eds). Vernacular Heritage and Earthen Architecture: Contributions for Sustainable Development, London (UK): Taylor \& Francis Group (pp. 663668).

Correia, M. R. A. R., Walliman, N. S. R., 2014: Defining criteria for intervention in earthen-built heritage conservation.
International Journal of Architectural Heritage, 8(4), 581-601. London (UK): Taylor \& Francis. DOI: 10.1080/15583058.2012.704478.

D'Ayala, D., 2014: Conservation Principles and Performance Based Strengthening of Heritage Buildings in Post-event Reconstruction Perspectives on European Earthquake Engineering and Seismology (pp. 489-514): Springer.

Dowling, D., 2004: Adobe housing in El Salvador: Earthquake performance and seismic improvement. In W. I. Rose, J. B Bommer, D. L. López, M. J. Carr, J. J. Major (Eds.), Natural Hazards in El Salvador. U.S.A.: Geological Society of America.

EERI., 2004: Preliminary Observations on the Bam, Iran, Earthquake of December 26, 2003. Oakland, CA.

Feilden, B. M., 2003: Conservation of Historic Buildings (3rd ed.). Oxford; Burlington, MA: Architectural Press.

GCI, T. G. c. i., 2015: MASTERING THE MECHANICS OF THE PAST- A Discussion about Preservation Engineering. THE GCI NEWSLETTER (Vol. 30).

ICOMOS-ISCARSAH Recommendation, 2005 Recommendations for the analysis, conservation and structural restoration of architectural heritage.

ICOMOS, 2003: Principles for the Analysis, Conservation and Structural Restoration of Architectural Heritage. Victoria Falls, Zimbabwe.

ICOMOS, 2010: Lima Declaration for disaster risk management of cultural heritage.

Illampas, R., Ioannou, I., Charmpis, D. C., 2011: Overview of the Pathology, Repair and Strengthening of Adobe Structures. International Journal of Architectural Heritage, 7(2), 165-188. doi:10.1080/15583058.2011.624254

Maïni, S., 2004: The French contribution to the reconstruction of Bam and its citadel : diagnosis of damages to vaulted structures Arg-e Bam and Bam town, Iran.

Manafpour, A. R., 2003: The Bam, Iran Earthquake of 26 December 2003. Retrieved from https://www.istructe.org/downloads/resources-centre/technicaltopic-area/eefit/non-eefit-reports/bam-earthquake-iran-by-alimanafpour.pdf

Michiels, T. L. G., 2015: Seismic Retrofitting Techniques for Historic Adobe Buildings. International Journal of Architectural Heritage, 9(8).

Minke, G., 2001: Construction manual for earthquake-resistant houses built of earth (G.-B. B. A. S. a. I. N. a. G. GmbH Ed.).

Montes, C. A., Giesen, C. G., 2010: Recommendations for the conservation of earthen architectural heritage in Chile. Advanced Materials Research, 133-134, 1125-1130.

Morris, H. W., Walker, R., Drupsteen, T., 2011: Modern and Historic Earth Buildings: Observations of the 4th September 2010 Darfield Earthquake. Paper presented at the Ninth Pacific Conference on Earthquake Engineering Building an Earthquake-Resilient Society Auckland, New Zealand. Retrieved from http://nzsee.org.nz/db/2011/133.pdf 
Okten, B. B., Okten, M. S., Haydaroglu, C., Benzoni, G., 2016: Structural engineering perspective on historic building restoration. Paper presented at the The First European and Mediterranean Structural Engineering and Construction Conference, Istanbul, Turkey.

Oliver, A., 2008: Conservation of Nondecorated Earthen Materials. In E. Avrami, H. Guillaud, M. Hardy (Eds.), Terra Literature Review. Los Angeles: Getty Conservation Institute.

Sathiparan, N., Meguro, K., 2015: Strengthening of adobe houses with arch roofs using tie-bars and polypropylene band mesh. Construction and Building Materials, 82, 360-375.

SESOC., 2013: Building seismic performance: Submission to the ministry of business, innovation and employment 8 March 2013. Retrieved from http://sesoc.org.nz/documents/SESOCBuilding-Seismic-Performance-Consultation-Documentfinal.pdf

Sumanov, L., 1999: Conservation and seismic strengthening of architectural heritage: Byzantine churches of the ninth till the fourteenth centuries in Macedonia. (PhD thesis), York: The University of York

Tolles, E. L., 2006: Seismic Retrofit Applications of Getty Seismic Adobe Project Technology to Historic Adobe Buildings. In M. Hardy, C. Cancino, G. Ostergren (Eds.), Proceedings of the Getty Seismic Adobe Project 2006 Colloquium (pp. 159-164). Los Angeles: Getty Conservation Institute.

Tolles, E. L., Kimbro, E. E., Ginell, W. S., 2003: Planning and engineering guidelines for the seismic retrofitting of historic adobe structures. Los Angeles: Getty Conservation Institute.

Tolles, E. L., Kimbro, E. E., Webster, F. A., Ginell, W. S., 2000: Seismic Stabilization of Historic Adobe Structures Los Angeles: Getty Conservation Institute.

Torrealva, D., Vargas-Neumann, J., Blondet, M., 2006: Earthquake resistant design criteria and testing of adobe buildings at Pontificia Universidad Catolica del Peru. In M. Hardy, C. Cancino, G. Ostergram (Eds.), Proceedings of the Getty Seismic Adobe Project 2006 Colloquium (pp. 3-10). Los Angeles: Getty Conservation Institute

UNESCO, I., ICOMOS, IUCN., 2010: Managing Disaster Risks for World Heritage: United Nations Educational, Scientific and Cultural Organization.

UNIPD, U. o. P., 2012: NIKER. Deliverable 5.5, Parametric assessment and optimized design procedures for floors and vaults. . Retrieved from http://www.niker.eu/

Vargas-Neumann, J., 2012: Principles for the Conservation of Earthen Architectural Heritage in Seismic Areas. Paper presented at the 15th World Conference on Earthquake Engineering, Lisbon. Retrieved from http://www.iitk.ac.in/nicee/wcee/article/WCEE2012_1746.pdf

Vargas-Neumann, J., Blondet, M., Iwaki, C., 2010: Intervention of Earthen Heritage in Seismic Areas and the Conservation Charters. Advanced Materials Research 133-134, 727-734. doi:10.4028/www.scientific.net/AMR.133-134.727
Vargas-Neumann, J., Dandona, B., Blondet, M., Cancino, C., Iwaki, C., Morales, K., 2011: An Experimental Study of the Use of Soil-Based Grouts for the Repair of Historic Earthen Walls and a Case Study of an Early Period Buddhist Monastery. In L. Rainer, A. B. Rivera, E. D. Gandreau (Eds.), Terra 2008: The 10th International Conference on the Study and Conservation of Earthen Architectural Heritage (pp. 301). Los Angeles: Getty Conservation Institute.

Varum, H., Tarque, N., Silveira, D., Camata, G., Lobo, B., Blondet, M., Costa, A., 2014: Structural Behaviour and Retrofitting of Adobe Masonry Buildings. In A. Costa, J. M. Guedes, H. Varum (Eds.), Structural Rehabilitation of Old Buildings (Vol. 2, pp. 37-75). Berlin: Springer Berlin Heidelberg.

Vatandoust, R., Mokhtari, E., Nejati, M., 2008: Consolidation and Reinforcement of Destabilized Earthen Structures in Bam after the Earthquake of December 2003: Some New Approaches In L. Rainer, A. B. Rivera, D. Gandreau (Eds.), Terra 2008: 10th International Conference on the Study and Conservation of Earthen Architectural Heritage. Los Angeles: Getty Conservation Institute.

Webster, F. A., 2008: Earthen Structures: Assessing Seismic Damage, Performance, and Interventions. Terra Literature Review, 69

Webster, F. A., Tolles, E. L., 2000: Earthquake damage to historic and older adobe buildings during the 1994 Northridge, California Earthquake. Paper presented at the 12th World Conference on Earthquake Engineering. Retrieved from http://www.iitk.ac.in/nicee/wcee/article/0628.pdf 